UCRL- 92924

PREPRINT

CONF-850759-16

\title{
FLUIDS AT HIGH DYNAMIC PRESSURES AND TEMPERATURES
}

W. J. NELLIS, D. C. HAMILTON, R. J. TRAINOR

H. B. RADOUSKY, A. C. MITCHELL, and H. C. HOLMES

Lawrence Livermore National Laboratory

University of California

Livermore, CA 94550

This paper was prepared for submittal to

Proceedings of the $x$ th AIRAPT High Pressure

Conference on Research in High Pressure

Science and Technology

Amsterdam, The Netherlands

July B-11, 1985

June 1985

This is a preprint of a paper intended for publication in a journal or proceedings. Since changes may be made before publication, this preprint is made available with the understanding that it will not be cited or reproduced without the permission of the author. 
FLUIDS AT HIGH DYNAMIC PRESSURES AND TEMPERATURES

W. J. NELLIS, D. C. HAMILTON, R. J. TRAIMOR, +

H. B. RADOUSKY, A. C. MITCHELL, and N. C. HOLMES

Lawrence Livermore National Laboratory University of California, Livermore, CA 94550

UCRL -92924

ABSTRACT

DE85 014812

Electrical conduçtivity data for shocked liquid nitrogen, Hugoniot data for

liquid air, shock temperatures for liquid ammonia, and double-shock equationof-state data for Al are discussed.

\section{DISCLAIMER}

This report was preparisd as an account of work sponsored by an agency of the United States Government. Neithe: :he United States Goveriment nor any agency thereof, nor any of their employees, makes any warrarty, express or implied, or assumes any legal liability or responsibility for the accuracy, completeness, or usefulpess of any information, apparatus, product, or process disclosed, or represents that its use would not infringe privately owned rights. Reference herein to any specific commercial product, process, or service by trade name, trademark, manufacturer, or otherwise does not necessorily constitute or imply its endorsement, recommendation, or favoring by the United States Government or any agericy thereof. The views and opinions of authors expressed herein do not necessarily state of :eflect those of the United States Government or any agency thereof. 


\section{INTRODUCTION}

Nitrogen undergues a continous dissociative phase transition above $30 \mathrm{GPa}$ shock pressure [1]. To obtain more information on this transition electrical conductivities of liquid nitrogen shocked to 20-50 GPa were measured. In order to investigate the effects of molecular impurities on this transition and to invesitgate the properties of mixtures, the Hugoniot equation of state of liquid air was aiso measured. The equation of state of $\mathrm{NH}_{3}$ is of importance for models of the outer planets Uranus and Neptune. $\mathrm{NH}_{3}$ is one of the "ices" thought to be a major component of these planets at interior pressures above $20 \mathrm{GPa}$ and temperatures greater then $2000 \mathrm{~K}$ [2]. We have measured the shock temperatures of 1 iquid $\mathrm{NH}_{3}$ at 48 and $61 \mathrm{GPa}$.

Aluminum was used as the equation-of-state reference material in shockimpedance-match experiments performed in proximity to underground nuclear explosions and discussed elsewhere in these proceedings [3]. In those experiments Hugontot data were obtained for Mo and $\mathrm{Cu}$ in the 1.5-2.5 TPa regton. In order to test the theoretical equation of state for $A$ i at the highest pressures available with our two-stage light-gas gun, double-shock experiments were performed on Al to $300 \mathrm{GPa}$. Al is most probably in the fluid phase in these experiments because Al melts on its Hugoniot at $150 \mathrm{GPa}[4,5]$.

\section{II . EXPERIMENT}

Shock waves were generated by means of a two-stage light-gas gun. The specimen holders for the electrical conductivity experiments used the electrode and trigger system described previously for water experiments [6]. 
For these liquid nitrogen experiments the electrode configuration was adapted to the cryogenic specinen holder described previously [7]. For conductivities below 0.1 (ohm-cm $)^{-1}$ a constant voltage neasuring circuit was used [B]. For higher conductivities a constant-current circult was used [6]. The liquid air Hugoniot data were obtained using the same system as for liquid nitrogen experiments [?]. The coolant was liquid $\mathrm{N}_{2}$. The air specimens had a fractional chemical composition of $0.781 \mathrm{~N}_{2}, 0.210 \mathrm{O}_{2}$, and $0.009 \mathrm{Ar}$ and were at $77.1 \mathrm{~K}$ initially. The 1 iquid $\mathrm{NH}_{3}$ shock temperature measurements were performed with a fast multichannel pyrometer using photonultiplier tubes. The coolent was cold $N_{2}$ gas [6]. The double-shock Al experiments were performed using Ta impactors and specimens which were composite of $A 1$ and a fa anvil. The first-shock state was obtained by measuring impactor velocity and impedance-matching the Hugoniots of $A 1$ and Ta $[y]$. The second shock state was obtained by measuring the shock velority in the Ta anvil.

III. RESULTS

Electrons are expected to be the dominant-conduc'cion mechanism in nitiogen and the electrical conductivity data were interpreted using a semiconductor model. Calcuiated shock temperatures [10] were used for this anaiysis, which yielded an efiective electronic energy gap of $5 \mathrm{ev}$ in the 
shock pressure range 20-30 GPa. The electrontc carrier concentration is of order $2 \times 10^{18} \mathrm{~cm}^{-3}$ at $20 \mathrm{GPa}$. Thus, at shock pressures below the dissociative transition at $30 \mathrm{GPa}$, the carrier concentration corresponds to about one carrier per $10^{4} \mathrm{~N}_{2}$ molecules. The energy absorbed in this carrier activation is insurficient to affect the equation of state, as was assumed previously for this range [10]. Analysis of the conductivity data in the transftion region above $30 \mathrm{GPa}$ wi?l be completed when our shock teinperature ineasurements are performed in this region.

The Hugoriot data for 1 iquid air are piotted in Fig. 1 as shock pressure versus molar volume. Also shown are the fits to the Hugonlot data for nitrogen [1] and oxygen [7]. The air point at $28 \mathrm{GPa}$ is in the molecular region for $N_{2}$ and is intermediate between the $N_{2}$ and $\mathrm{O}_{2}$ data, as expected. The air point at $65 \mathrm{GPa}$ is in good agreement with both the nitrogen and oxygen data. All three fluids, as well as carbon monoxide are apparently approaching a common limiting mole- volume at high shock pressures.

The shock temperature data for 1 lquid $\mathrm{NH}_{3}$ at $4000 \mathrm{~K}$ agree to within ten percent with theoretical calculations that neglect molecular dissociation-ionization. From electrical conductivity data at 7-28 6Pa [11], $\mathrm{NH}_{3}$ is known to fonize at high shock pressures and temperatures. Because of the small difference between the temperature data and theory, the energy absorbed in ionization is insufficient to affect significantly the thermal equation if state. A detalled paper on this $\mathrm{NH}_{3}$ work will be published elsewhere $[12 \bar{c}]$.

Additional results for shocked molecular fluids are discussed elsewhere in these proceedings, including the spontaneous Raman spectroscopy of shocked water [13] and the emission spectrosocpy of shocked benzene [14]. 
Equation-of-state data for $A 1$ shocked to $1 E 0 \mathrm{GPa}$ and double-shocked to $300 \mathrm{GPa}$ are shown in Fig. 2, plotted as shock pressure versus relative volume. Also plotted in Fig. 2 is the $300 \mathrm{~K}$-1sotherm calculated by Mcmahan [15] using electron band theory. This figure 111 ustrates how the themal pressure of the double-shock point is significantly less than the thermal pressure on the Hugoniot at the same volume. In a plot of pressure versus mass velocity, the double-shock point lies on the mirror reflection of the principal Hugoniot. The "mirror reflection" approximation to reshock curves and release isentropes is common at lower pressures. Deviations from this approximation are expected at higher pressures, but as yet we have not observed such deviations.

\section{ACKNOWLEDGEMENTS}

Work performed under the auspices of the U.S. Department of Energy by the Lawrence Livermore Hational Laboratory under contract number W-7405-ENG-48, with partial support for the liquid ammonia experiments from the U.S. National Aeronautics and Space Administration under contract number 83-033. 


\section{REFERENCES}

+ Present address: Los Alamos Nattonai Laboratory, Los Alamos, NH, B7545, U.S.A.

[1] W. J. Nellis, N. C. Holmes, A. C. Mitchell, and M. van Thiel, Phys,. Rev. Lett. 53 (1984) 1661 .

[2] D. J. Stevenson, Annu. Rev. Earth Planet. Sci. 10 (1982) 257.

[3] A. C. Mitche11, W. J. Nellis, R. A. Heinle, G. W. Repp, J. A. Moriarty, H. Ross, and N. C. Holmes, these proceedings.

[1] R. G. Mcqueen, J. M. Firtz, and C. E. Morris, in Shock Waves in condensed Matter-1983, edited by J. R. Asay, R. A. Graham, and G. K. Straub, Elsevier. Amsterdam, 1984, p. 95.

[5] J. A. Moriarty, D. A. Young, and M. Ross, Phys. Rev. B 30 (1984) 578.

[6] A. C. Mitchell and W. J. Nellis, J. Chem. Phys. 76 (1982) 6273.

[7] W. J. Nellis and A. C. Mitche11, J. Chem. Phys. 73 (1980) 6737.

[8] V. V. Yakushev, Soviet Combustion, Explosion, and Shock Waves 14 (1978) 131.

[9] A. C. Mitchell and W. J. Nellis, J. App1. Phys. 52 (1981) 3363.

[10] M. Ross and F. H. Ree, J. Chem. Phys. 73 (1980) 6146.

[11] A. C. Mitchell, M. I. Kove], W. J. Nellis, and R. N. Keeler, In High Pressure Science and Technology, edited by B. Vodar and Ph. Martineau, Pergamon, 0xford, 1980, p. 1043.

[12] H. B. Radousky, A. C. Mitche11, W. J. Ne11is, and M. Ross, to be published in the Proceedings of the 1985 Toptcal Conference on Shock Waves in Condensed Matter.

[13] N. C. Holmes, W. J. Nellis, W. B. Graham, and G. E. Walrafren, these proceedings.

[14] M. L. Johnson, M. F. NIcol, and N. C. Holmes, these proceedings.

[15] A. K. McMahan, Bu11. Am. Phys. Soc. 21 (1976) 1303. 


\section{Figure Captions}

Fig. I Hugioniot data for liquid air. Also plotted are fits to the data for liquid nitrogen and oxygen.

Fig. 2. Double-shock data point (open circle) for Al. The solid circle is the first shock state. 


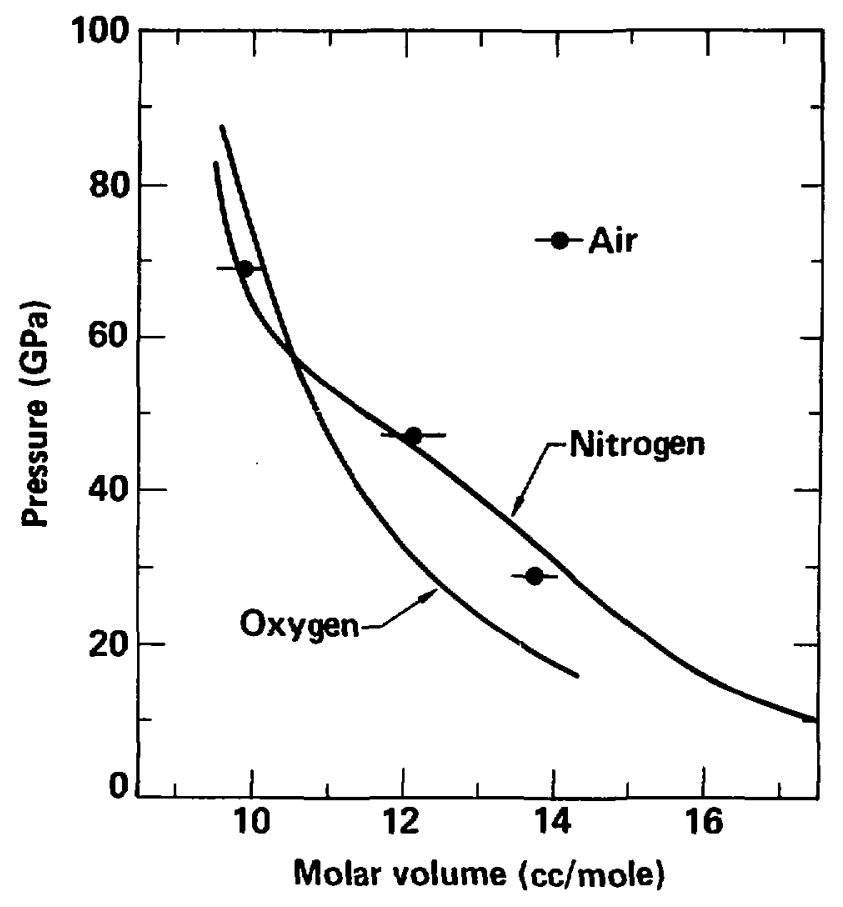

Figure 1 


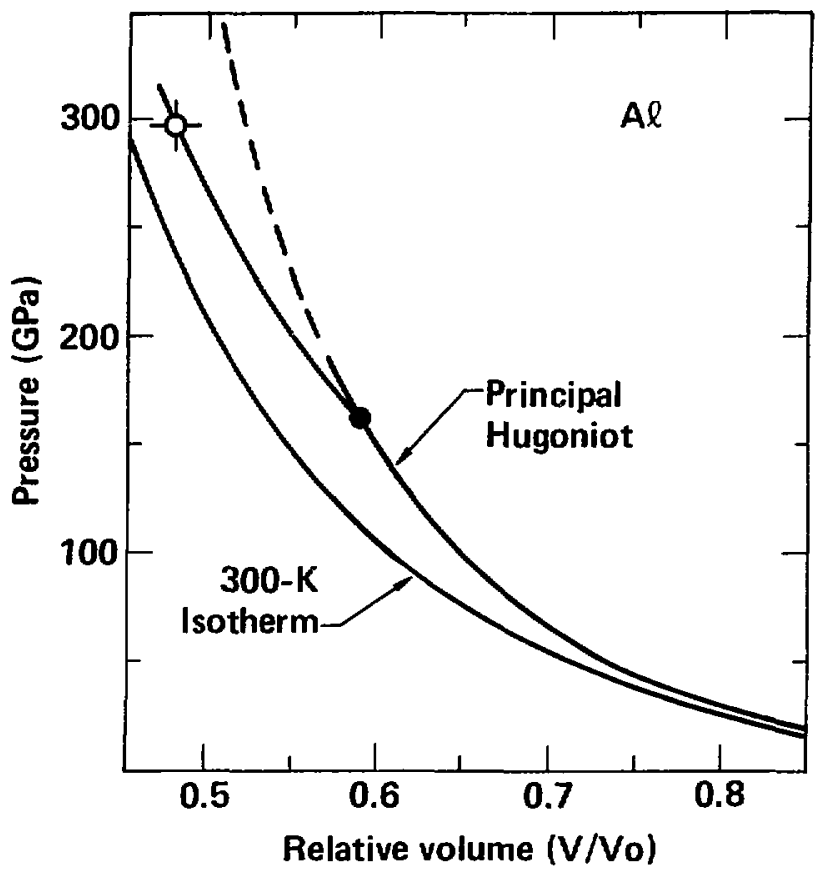

Figure 2 